Journal of the Statistical and Social Inquiry Society of Ireland

Vol. XXIX

\title{
VOLATILITY AND THE EURO: AN IRISH PERSPECTIVE
}

\author{
JOHN COTTER \\ University College Dublin
}

(read before the Society, 17 February 2000)

\begin{abstract}
How volatile is the euro currency? Given Ireland's open economy status and its strong trading dependency on economies outside the euro area, understanding this question is vital. The paper analyses the volatility levels facing Irish economic agents by comparing the experiences from membership of the European Monetary System (EMS) through to the new single currency. The focus is on measuring volatility using two methodologies - Conditional Variance GARCH models and Extreme Value Theory models. It shows that whilst average volatility levels of the euro exceed the Irish pound's experience within the EMS, the probability that fluctuations such as those that arose during the currency crises of 1992/93 now appear less likely to occur.
\end{abstract}

Keywords: Currency Volatility, GARCH, Extreme Value Theory.

JEL Classifications: C320, F310, G150.

\section{INTRODUCTION}

With Ireland joining European Monetary Union (EMU) and adopting the euro, exchange rate risk between participating Member States is gone. ${ }^{1}$ However, as is known, this new currency will continue to face exchange rate risk, and any general reduction of volatility on a day to day basis for Irish economic agents neglects to take account of possible extreme problems with the euro. In this paper we will see that even though the euro is a managed, or irrevocably fixed, system, trade between Ireland and non-members, most notably the UK and the US, involves two separate currencies. This trade will require currency trading, leading to the possibility of large downside exposure to exchange rate risk for Irish firms. In addition, dealings in capital markets may be inhibited thereby reducing the funds available for investment purposes.

The issue of currency volatility is important for policy-makers, as high levels will generally reduce economic growth. Causes of an economic slowdown may be due to a reduction in investment, or firms setting prices too high in an attempt to satisfy their risk aversion. Two recent examples of exchange rate volatility show the 
downside implications of large currency changes. First is the experience of the Mexican peso disaster that reduced that country's real output by 6 percent in 1995 . $^{2}$ Second, with more relevance to the Irish economy, is the 1992/93 crises of the EU Exchange Rate Mechanism (ERM) where failed attempts to avert forced devaluation cost all participating members between $£ 100$ billion and $£ 150$ billion. These two examples show the power of speculators in exchange rate trading, and there is no reason to believe that the creation of a single currency will eliminate this type of activity in the foreign exchange markets.

The methodological approach relied on in this paper is two-fold. First, conditional volatility is measured using a Generalised AutoRegressive Conditional Heteroskedasticity (GARCH) model. This will demonstrate the extent to which exchange rate movements have varied over time, with periods of low and high volatility. Second, exchange rate fluctuations are examined using Extreme Value Theory (EVT). This in essence determines exchange rate fluctuations allowing for the true data characteristics to be imbedded in the calculations. With EVT the more common or average levels of volatility are not primarily of concern to economic agents as they are reasonably small in nature, and only have minor policy implications. Rather, it is large exchange rate movements that are of concern, as these can impact economic activity to a large degree. ${ }^{3}$

A graphical example will illustrate what is being calculated, and its importance. In Figure 1 nominal exchange rates increase or decrease, and these changes can be large or small, with the relative frequency of any fluctuation measured by probability levels. As we can see, the large fluctuations do not occur frequently, but they do have a major impact on an economy, and it is the shaded areas that are of interest to us.

Volatility levels are analysed for different exchange rate regimes using bilateral nominal exchange rate data involving the Irish pound. As Ireland's main trading partner is the UK, considerable attention is placed on analysing the pound/sterling relationship since 1979. This period of analysis covers both countries being part of the managed ERM (1990-92) as well as two separate periods surrounding this time frame where the currency control between these economies was less structured.

This examination can be compared to fluctuations in the euro by analysing future rates that are available since 1997 . Before proceeding to the analysis, a presentation of the stylised facts and a description of the general distributional properties of nominal exchange rates are introduced. Previous analysis of this type using a related methodology for Irish financial time series has been completed for the equity market (Cotter, 1998 and 1999).

This paper proceeds as follows. Section 2 gives a chronological description of the major events affecting the Irish pound since it formally broke the sterling link in 1979. This is followed in section 3 by a discussion of the problems that may occur 
from large levels of exchange rate volatility. Section 4 details the empirical characteristics of exchange rate series and how this paper addresses these issues. In particular, the lack of normality and the fat-tailed characteristic are discussed in conjunction with GARCH models and Extreme Value Theory.

Figure 1: Volatility and a Distribution of Exchange Rate Changes

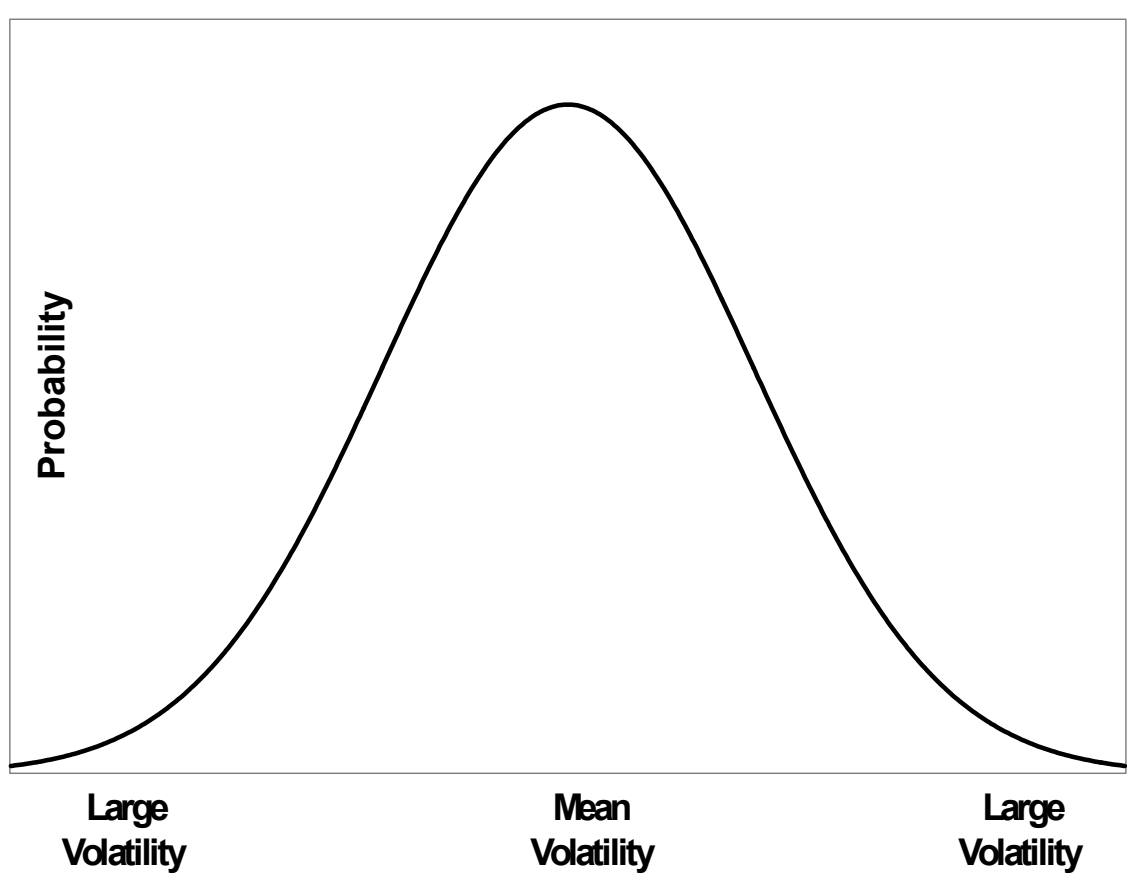

A basic description of the exchange rate series analysed is given in section 5. This is followed by a presentation of the empirical evidence where three sets of findings are discussed. In section 6 some preliminary statistics for a wide range of exchange rate series are given. Following this, the conditional volatility measures are presented in section 7, and finally the Extreme Value measure detailing the very larger exchange rate fluctuations are discussed in section 8. 


\section{A BRIEF HISTORY OF THE IRISH POUND}

Up until 1979 when Ireland joined the European Monetary System (EMS), the Irish Pound had inextricable connections with sterling. For instance, there was a common currency between 1826 and 1928, and thereafter both currencies traded at parity (Leddin and O' Leary, 1995). Thus, fluctuations in sterling were completely mirrored in the Irish case. As a result, Ireland was part of the Gold Standard between 1924 and 1931 which exhibited low volatility through fixed exchange rates, in contrast to the period of relatively high volatility between 1931 and 1944 when this system was abandoned. After this, the Bretton Woods system induced some calm into exchange rate price movements until this collapsed in 1971, thereafter resulting in more volatile markets. Thus whilst it is clear that these systems were initially set up to be permanent in nature, this cannot be taken for granted regardless of how irrevocable the system appears on its introduction.

Discussing the break of the link from sterling in more depth, it was decided to join the EMS in order to anchor the pound to the German mark. From this, it was envisaged that by tracking the German currency, the economic fundamentals enjoyed by Germany such as low inflation could also be tracked by the Irish economy. Previous fundamental disasters affecting the UK, such as high inflation; high interest rates; and most importantly, an unstable currency, had pointed to the advantages of adopting closer ties with the more stable German economy.

Characteristically, the EMS was an example of a managed exchange rate system that mixed floating market conditions with a stringent fixed mechanism. The system relied on the ability of a currency to float within a predestined band, for example \pm 2.25 percent, and movement beyond these rate changes were to be restricted through government intervention. Rules that had to be followed within the EMS were laid out in the ERM, which described the initial exchange rate each member economy got through its value in terms of a central currency, the European Currency Unit $(\mathrm{ECU})^{4}$. Each Member State's respective central bank, through the buying and selling of currency reserves, were the agents responsible for ensuring that the currency would not exceed the limits predefined by the ERM.

Initially, joining the EMS did not offer the Irish economy the benefits envisaged. This was due to the Irish authorities trying to stay within the ERM bands while retaining parity with sterling. This policy was short-lived ending within three weeks of its introduction. ${ }^{5}$ Thereafter, the pound's tracking of the mark suffered a credibility problem with Irish economic agents, including employers and unions, recognising that the strongest trading partner were not EMS countries, but rather, the UK (Power, 1999). This lack of credibility is demonstrated by Ireland's four realignments during the 1980's. As a consequence, the Irish economy suffered detrimentally during much of the decade with high unemployment, and relatively 
high interest rates and inflation vis-à-vis Germany. These empirical features go against the arguments that are usually presented in favour of low exchange rate volatility arrangements, namely that it induces economic growth. As we will see, the volatility in currency markets is greater for floating regimes in comparison to their managed counterparts, although the extreme values are actually greater for the latter system.

Between 1987 and 1992, exchange rate stability for the pound was ensured. Thereafter, the bands of the ERM widened to \pm 15 percent, allowing for large levels of exchange rate fluctuations without the intervention of a country's monetary authority. In practice, central banks allowed currencies to be part of a 'soft' exchange rate zone with wide fluctuations being allowed over the short run, and stability being provided by narrow fluctuations in the long run (Bartoline and Prati, 1999). For example, this policy was applied during the peso crises in 1995 where the Irish pound was allowed to depreciate against the mark. After Ireland agreed to join EMU, much of the analysis over the last few years has concentrated on advantages and disadvantages of this decision. Turbulence facing the pound has been moderate and on December 31, 1998 the Irish currency was confined to history, and the euro took its place.

What actually caused the band to be widened was the collapse of the EMS in August 1993 brought about through intense speculative activity on currency markets. Ireland unfortunately suffered extensively during the 1992/93 crises that preceded the collapse and it is worth detailing the events surrounding it as a demonstration of how exchange rates can go through periods of heavy turbulence even when there is a system that is set up to eliminate this feature.

This shows up two important considerations when thinking about the history of Irish exchange rate policies. First, the divergence between sterling and the mark was central to the currency problems and their impact on the Irish economy. Ireland's attempt to track the mark to attain macro stability, and sterling to remain competitive with their main trading partner, was unfeasible anytime that sterling became unstable. The fact that sterling was part of the EMS should have implied that the Irish authorities were now within a formal system that allowed them to achieve their goal of importing the positive macro fundamentals experienced by Germany, while remaining competitive in trading with the UK. However, the actions of the Bundesbank in trying to support the unification of Germany were unacceptable to the UK government, and they abandoned the system in 1992.

Second, and more importantly in the context of this paper, Table 1 indicates that while exchange rate volatility can sometimes be controlled, it can never be totally eliminated. The EMS, which had the support of the central European economies, was unable to defend individual currencies against speculative attacks. Within a time frame of almost a year, involving major government intervention trying to maintain exchange rate stability, the speculators successfully targeted currency after 
currency, and through sheer trading volume were able to defeat any policy initiative or trading stance that was put up against them. In the case of the pound, belligerent statements against the speculators by government, unions and employers alike, the use of extensive currency reserves in open market operations, and major adjustments to its key monetary variables together were not enough in their goal of defeating the currency traders. The exchange rate movements resulting from this speculation had a detrimental affect on the Irish economy and led to the view by many commentators that this type of closely managed system led to opportunities for intense speculative activity which could not be withstood.

Table 1: A Chronology of the EMS Crises, 1992-1993

\begin{tabular}{|c|c|}
\hline Date & Event \\
\hline \multicolumn{2}{|l|}{1992} \\
\hline June 2 & Denmark referendum rejects Maastricht Treaty. \\
\hline July 16 & $\begin{array}{l}\text { German discount rate increases to } 8.75 \text { percent leaving a } \\
\text { differential of } 6.75 \text { percent over US rate, }\end{array}$ \\
\hline August 20 & Sterling rate falls to floor of ERM band. \\
\hline September 5-6 & $\begin{array}{l}\text { After a lack of intervention by the Bundesbank, an EC meeting } \\
\text { ends with no sign of German appeasement to strong demands } \\
\text { for action by UK. }\end{array}$ \\
\hline September 16 & $\begin{array}{l}\text { UK suspends sterling's participation in EMS after numerous } \\
\text { attempts to maintain the currency's value within ERM bands. }\end{array}$ \\
\hline September 17 & $\begin{array}{l}\text { Irish pound falls to floor of allowable ERM bands while Italy } \\
\text { suspends the lira's participation. }\end{array}$ \\
\hline September 24 & $\begin{array}{l}\text { Ireland imposes capital controls, which has no impact on the } \\
\text { pound's value. }\end{array}$ \\
\hline November 23 & Central Bank of Ireland, amongst others, raises interest rates. \\
\hline December 3-28 & $\begin{array}{l}\text { Intensive speculative pressure put on pound and other } \\
\text { currencies. }\end{array}$ \\
\hline \multicolumn{2}{|r|}{ 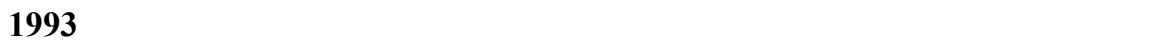 } \\
\hline January 6 & $\begin{array}{l}\text { Central Bank of Ireland raises official interest rate to } 50 \\
\text { percent. }\end{array}$ \\
\hline January 7 & $\begin{array}{l}\text { Central Bank of Ireland raises official interest rate to } 100 \\
\text { percent. }\end{array}$ \\
\hline January 28 & $\begin{array}{l}\text { Central Bank of Ireland again raised official interest rate to } 100 \\
\text { percent after it was cut in mid-January. }\end{array}$ \\
\hline January 30 & Irish Pound devalued by 20 percent. \\
\hline July 31-August 1 & $\begin{array}{l}\text { After EC finance ministers meet, the EMS band is widened to } \pm \\
15 \text { percent. }\end{array}$ \\
\hline
\end{tabular}




\section{PROBLEMS OF LARGE LEVELS OF EXCHANGE RATE VOLATILITY}

A number of disadvantages result from large fluctuations in exchange rates. These normally come under the heading of microeconomic factors dealing with trade including a reduction in investment; risk averse firms setting too high a price; poor price signalling leading to expensive search costs; and a reduction in foreign investment for domestic capital markets (Honohan and Lane, 1999). It is necessary to discuss these at more length and see the extent to which they occur. To set the importance of exchange rate volatility in context, Table 2 shows the importance of external, non-euro trade for individual members of EMU. As we can see, Ireland's reputation of being an open economy is very much focused on trading relationships with non-euro partners, and this activity as both a percentage of GDP and total trade outweighs that of the other single currency participants. Ireland's booming economy is very much driven by our external trading activity. This implies that Ireland is very much exposed to fluctuations in the euro with the currencies of its trading partners. Any problems with the euro currency will have major implications for Ireland's external trade balance. However, if the UK joins EMU this would very much reduce this concern given the very strong trading relationship there is between the two economies.

Table 2: Non Euro Area (NEA) Trade 1998

\begin{tabular}{lcc}
\hline & NEA Trade/GDP $\%$ & NEA Trade/Total Trade \% \\
\hline Ireland & 85 & 64 \\
Belgium/Luxembourg & 50 & 39 \\
Netherlands & 48 & 45 \\
Finland & 39 & 65 \\
Germany & 26 & 55 \\
Austria & 22 & 29 \\
Italy & 20 & 52 \\
France & 20 & 47 \\
Portugal & 19 & 33 \\
Spain & 17 & 41 \\
\hline
\end{tabular}

Source: EUROSTAT (2000).

Concentrating more fully on the problems encountered by large levels of exchange rate volatility raises a number of issues. A simple example can illustrate the costs incurred by consumers in exchange rate transactions. The European political establishment in favour of a single currency, suggested that the transaction costs of exchanging currencies within the EMS countries was worth 0.5 percent of EU GDP (European Economy, 1990). Intra-EU exchange rate volatility was the cause of this loss. Now these costs are eliminated within EMU, they still occur between euro zone members and non-members, for example between Ireland and the UK. ${ }^{6}$

However, there are two commonly used arguments that negate against this 
hypothesis. First, hedging products are available that diversify against or eliminate exchange rate risk. ${ }^{7}$ Whilst these are not costless assets, their popularity would suggest that they are perceived to be successful in reducing exchange rate risk. At the very least, an upper limit of risk effects is set in place, similar in purpose to the bands of the ERM. Countering this, we are still dealing with imposing expenses, however small these may be, to counteract currency fluctuations. Second, volatility in exchange rates between two economies does not imply volatility for all bilateral rates. Thus an economic agent can shift their consumption choice away from markets involving volatile currency movements that result in blurred pricing policies, to suppliers in other economies. However, whilst this may imply that world consumption is not affected by specific cases of bilateral currency fluctuations, trade between the economies with volatile exchange rates is affected. Assuming the volatile case involves the euro, then Ireland will be affected considerably according to the data in Table 2 .

Now examining the impact of exchange rate instability in a more formal context, we can start by noting that changes in economic growth and international trade are positively related (Sachs and Warner, 1995). This implies that a reduction in economic activity between countries reduces the welfare of their citizens. It is clear that both a decrease in investment, and uncompetitive prices being charged by risk adverse firms, due to nominal exchange rate fluctuations lead to a downturn in economic growth. Risk adverse agents will be put off extra intermediate consumption in the case of firms, and further final consumption in the case of households due to the uncertainty caused by currency fluctuations.

Supporters of a single currency as a prerequisite for a single European market have always cited the lack of competitive pricing caused by volatility in Member State currencies. Unclear pricing signals led to unnecessary search costs that put the consuming economic agent at a disadvantage. These search costs were beneficial for domestic suppliers who could shield inefficiencies through their newly acquired extra market power. Removing these currency-induced distortions would enhance the competitive behaviour of the euro zone countries leading to increased economic growth. Other micro distortions that result in blurred price signalling include tax and labour market ones, resulting in a similar downturn in economic activity. The measurement of these distortions in economies is very difficult to compute however, as they are second order influences and their accurate forecasting is unresolved (Flood and Rose, 1995). ${ }^{8}$

Liquidity in financial markets also is affected by exchange rate fluctuations. There is a negative relationship here with increased volatility leading to reduced trade in financial products. First, this will worsen borrowing conditions for firms in domestic markets as foreign investment in these markets is reduced due to the exchange rate risk. Obviously, this will again reduce domestic economic growth. Second, the lack of financial market liquidity will reduce the choice of financial products available. Thus, risk management practices will neither be as wide ranging 
or efficient as a result, again leading to reduced economic growth (Obstfeld, 1994). Specifically, a lack of efficient risk management practices on an international scale that would provide effective hedging against exchange rate crises is of paramount importance given the relatively recent currency crises in Europe and Asia. ${ }^{9}$

\section{STYLIZED FACTS OF NOMINAL EXCHANGE RATES}

This section outlines the previous evidence on the time series properties of exchange rates. Two fundamental findings are made, namely that volatility clustering occurs and the tail behaviour of an exchange rate's first difference is non-Gaussian, or nonnormal. First, volatility clustering implies that periods of turbulence (tranquillity) are followed by further periods of turbulence (tranquillity). The introduction of GARCH models, and their concentration on second moment dependence, has led to this characteristic being commonly used as part of the exchange rate modelling process. ${ }^{10}$ The second characteristic is usually referred to as the 'fat-tail puzzle' where an asset exhibits too many extreme returns in comparison to a normal distribution. Evidence of this property for currency time series also suggests that the extent to which a distribution of exchange rate returns exhibit fat tails reduces with the extent to which the currency is allowed to float (Koedijk and Kool, 1994). Thus, the stricter the regime, the greater the fat-tail characteristic.

\section{Modelling of Time-Varying Volatility}

The seminal development of examining time-varying volatility owes much to the ARCH model of Engle (1982). The process is formally outlined in Appendix A. Realistic descriptions of volatility persistence could now be examined by allowing the conditional variance to be time dependent as would be expected given the uncertainty that exists in the formation of exchange rates. Bollerslev's (1986) extension to the ARCH model allowed the conditional variance to be also dependent on past levels of the conditional volatility estimates. The GARCH $(p, q)$ process is also outlined in Appendix A. ${ }^{11}$ This study chooses a GARCH $(1,1)$ specification to obtain conditional volatility forecasts.

The main advantage for the context of this analysis is that if the conditional variance is to change for any reason over time these models are inherently set up to deal with such an event. This is critical for the modelling of the Irish pound, given the changes that have occurred during its history. Taking the 1992/93 currency crises as an example, volatility in European currencies increased dramatically. This was more pronounced for the pound given its attempt to closely track a currency, the mark, which remained within the EMS, and sterling that diverged on its own path by leaving the system.

\section{Fat-tails and Risk Analysis}

In many situations, the long-term risk of a venture is an important consideration of the decision making process. Take for example, the implication that Ireland's 
membership of the EMS would result in lower volatility vis-à-vis a floating system has been seen as an advantage in terms of international trading possibilities and capital movements into the economy. The rational for this implication is that over sustainable periods of time, but not necessarily immediately, or at any particular moment in time, the pound's exchange rate fluctuations with its trading partners would be smaller. So policy makers recognised that problems would occur at the beginning of Ireland's EMS membership given its previous ties with sterling, and also that they may occur at any time during its membership given that realignments were to be allowed under exceptional circumstances. An analysis of long term risk in such a system requires the examination of its unconditional distribution.

A wide range of techniques can be used in measuring the fluctuations of an unconditional distribution of exchange rate changes. The most common approach in the empirical literature is to assume that exchange rate behaviour approximates a particular standard statistical form, known as the normal distribution. Any derived economic implications from exchange rate movements are calculated on the basis of assumptions underlying this distribution. In reality, exchange rates, as well as other financial asset data, do not have all the properties of the normal variable. The main weakness is referred to as the 'fat tailed' characteristic and its importance cannot be understated as noted by the Chairman of the US Federal Reserve Bank, Alan Greenspan (1997) "the biggest problem we now have with the whole evaluation of risk is the fat-tailed problem". This concept can be clearly seen in Figure 2 where the actual changes in exchange rates are imposed on a normal distribution.

Here, the probability mass for the fat tailed situation is greater around the tails vis-àvis the normal distribution situation. This implies that volatility levels calculated assuming normality would be less (and incorrectly so) than that which reality dictates. Inferences regarding future volatility would suffer a similar problem. In contrast, our approach using Extreme Value Theory allows for the fat tailed situation. Rather than fully outline the operations of Extreme Value Theory, the main characteristics are discussed here with further results available in Appendix B.

We want to determine probabilities of exchange rate fluctuations reaching a certain magnitude. The greater the magnitude, the greater the levels of volatility. Looking at Figure 1, we have made two cut-off points where the currency appreciates (depreciates) by a large amount. Assuming that these thresholds each represent a certain percentile of all first differences analysed for a particular currency, we can use Extreme Value Theory to provide accurate information on a number of issues. We can examine a spectrum of arbitrary cut-off points, and determine the probability of exceeding this level of exchange rate changes using the Excess Probability estimator. The expression used to calculate this is given in Appendix B. Comparisons can then be made for currencies with different volatility levels.

The advantage of using Extreme Value Theory is that the exact distributional form of the asset being analysed does not have to known. Rather, we assume that there is 
convergence at the limit to one of three types of distribution, including one with fattailed characteristics. Convergence to the fat-tailed distribution is similar to the use of the central limit theorem with Extreme Value Theory relying on order statistics, whereas the latter deals with averages. In order to obtain the excess probability measure a tail estimate is required. ${ }^{12}$ The semi-parametric Hill Tail Index is the efficient measure, and is chosen from a range of moment estimators (Kearns and Pagan, 1997). ${ }^{13}$ This estimator is given in Appendix B.

Figure 2: Fat-tailed and Normal Distributions

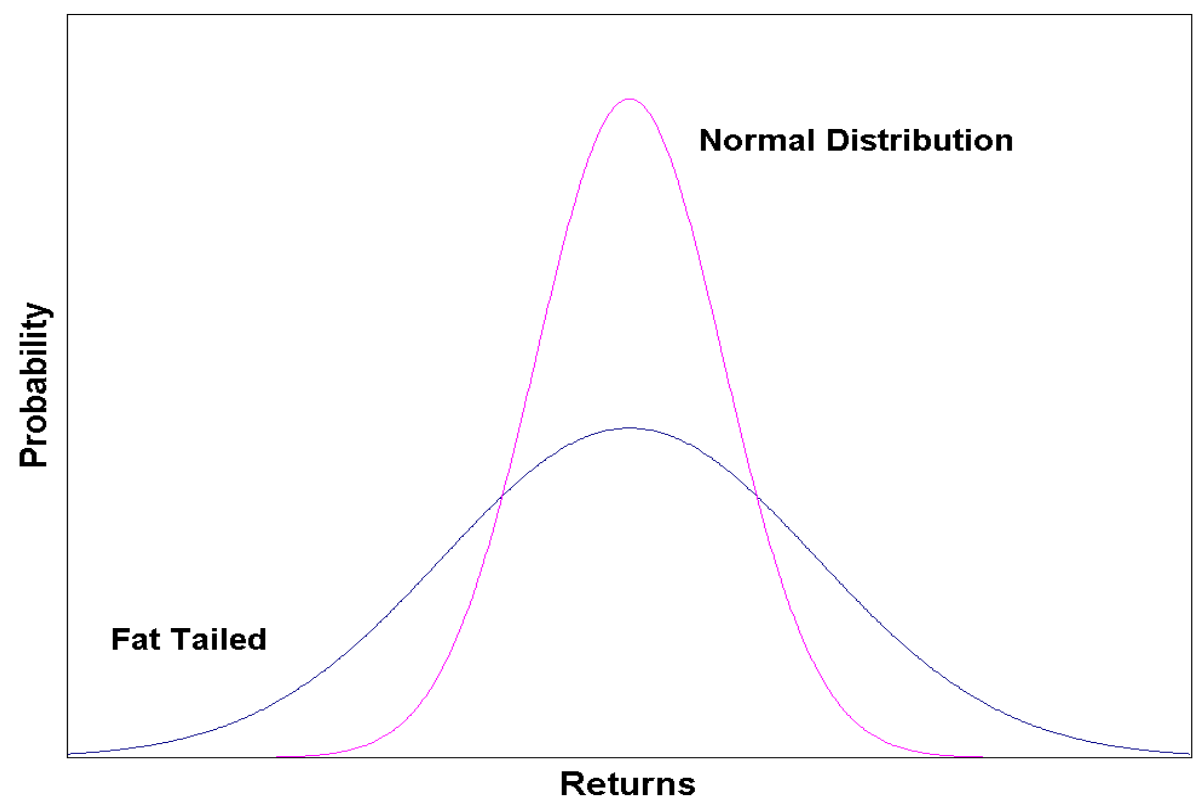

Extreme Value Theory is used to address nominal exchange rate stability in two ways in this paper. First, it examines volatility levels of different exchange rate regimes, under two broad headings, floating and managed. In particular, it determines a worst case scenario at a given confidence interval and the length of time over which this event should occur. For example, the following type of statement could be made. There is a one percent chance (probability 0.01) that daily exchange rate fluctuations are in excess of ten percent for a regime every ten years. From this type of analysis, volatility levels can be compared for various exchange rate systems. Past evidence (for example, Flood and Rose, 1998) suggest that in general floating nominal exchange rates result in average fluctuations that are greater than their managed counterparts. This is intuitively true - managed systems rule that the rate fluctuates to a certain degree, and thereafter, intervention takes 
place to limit the exchange rate changes; but it does not take account of realignments or even worse, the managed system collapsing. Such crises in exchange rate markets are not supposed to happen, but unfortunately, reality dictates that they do. These incidents result in extreme volatility levels leading to massive costs for the economic agents affected.

Second, and related to the issue of exchange rate fluctuations, a spectrum of excess probability levels is provided at different volatility levels. This provides information for a comparative analysis of volatility levels inherent in alternative exchange rate systems, and policy makers can now see that exchange rate stability is of concern not just in the past, but more importantly, also in the future. That is, by using the Extreme Value approach, we can quantify a range of volatility possibilities at different confidence intervals. And the decision maker, whether they are an exporting firm or giving advice to the Department of Finance, can make their contribution by taking account of their risk preferences. For example, a highly risk averse exporter would try to introduce techniques such as hedging (or in an extreme case, change their trading strategy by concentrating on the domestic market) so as to combat the projections of exchange rate fluctuations as calculated by our technique.

\section{DATA CONSIDERATIONS}

Overseeing the analysis in this paper is a comparison of the Irish experience as part of the EMS, and possible future experiences under the euro. Spot exchange rates are chosen, as these are the variables that clear the market between importers and exporters. The euro futures contract is chosen due to lack of sufficient data available for the underlying asset. Before, determining the conditional volatility levels inherent in different nominal exchange rates, some preliminary findings are presented for a number of currency series. These series are presented in Table 3 giving the respective time periods of analysis.

Five exchange rate series, four spot and one futures, are chosen to indicate different relationships that have affected Ireland in the past, and may also in the future. ${ }^{14}$ The two main currencies that the Irish pound has had formal links with, the mark and sterling are included. The US dollar represents the currency of the main economy of the world, and has a major influence on world capital movements. The Argentine peso is included, not for reasons involving major economic interactivity between Ireland and Argentina, but rather, to indicate a more volatile relationship of which exchange rates are capable of. As well as the interest rate parity conditions that require focusing on in the futures series, the euro-dollar rate is chosen to indicate investors perceptions on the development of this new currency. This exchange rate also describes the levels of volatility that Irish economic agents may face over time. 
Table 3:Exchange Rate Series

\begin{tabular}{ll}
\hline Currency & \multicolumn{1}{c}{ Time Period } \\
\hline Euro & May 1997-October 19999 \\
Sterling & March 1979-December1998 \\
Deutsche Mark & March 1987-December 1998 \\
Dollar & March 1987-December 1998 \\
Argentine Peso & March 1987-December 1998 \\
\hline
\end{tabular}

Initially, the euro-dollar rate is available from May 1997 to October 1999. Dealing with the spot rates, we identify three separate time periods encompassing the lifetime of Ireland's participation in the EMS. First, there was the period between March 1979 and February 1987 where realignments within the system were commonplace, with the pound trying to track two diverging currencies, sterling and the mark. Second, involved a more coherent approach by participating members between March 1987 and September 1993, but also including the currency crises that led to the major revamping of the EMS ${ }^{15}$ Finally, the third sub-period focuses on the time frame between October 1993 and the conclusion of the EMS in December 1998. The bands of the ERM were widened in this period for exchange rate movements up to 15 percent, but in practice, governments followed a 'soft' exchange rate policy that allowed for large short run fluctuations, while at the same time, constraining long run changes to narrow bands.

\section{PRELIMINARY FINDINGS}

Some preliminary statistics for the exchange rate series are presented in Table 4. All currencies exhibit excess kurtosis and a lack of normality regardless of time period. $^{16}$ The excess kurtosis represents a distribution of exchange rate price changes that is peaked around the mean and is also fat-tailed. Time-varying volatility with periods of tranquillity and turbulence cause the leptokurtosis. ${ }^{17}$ The absence of normality implies using alternative processes to correctly model currency movements. Also, skewness is generally present for the series' analysed giving a non-symmetric distribution of returns. There is a slight discrepancy between the spot series and the euro in terms of the direction of the asymmetry of returns. The euro is significantly positively skewed indicating more positive price changes than negative ones. Nevertheless, the impact of these negative rate movements outweighs the positive ones as the euro has actually depreciated in value against the dollar since its inception. However this depreciation, measured by the mean value, is not significant.

The inter-quartile range gives a preliminary indication of the extent of exchange rate movements by focusing on the difference between the seventy-five and twenty-five percentiles. We see that the floating currencies indicate greater values for this statistic than those with a more rigid relationship, thereby supporting the view that the volatility of fixed mechanisms is less than their flexible counterparts. More 
importantly, in the context of Ireland's history, the interquartile range of the euro is greater in magnitude than experienced by the pound-mark during its period of membership in the EMS. This is consistent with the finding for the pound-sterling rate.

Table 4: Summary Statistics for Exchange Rate Returns Series

\begin{tabular}{|c|c|c|c|c|c|c|}
\hline Currency & Mean & $\begin{array}{l}\text { Standard } \\
\text { Deviation }\end{array}$ & $\begin{array}{c}\text { Inter Q } \\
\text { Range }\end{array}$ & Skewness & Kurtosis & Normality \\
\hline \multicolumn{7}{|c|}{ FUTURES RATES } \\
\hline Euro & -0.02 & 0.59 & 0.72 & $0.43 *$ & $0.83 *$ & $0.06^{*}$ \\
\hline \multicolumn{7}{|c|}{ SPOT RATES } \\
\hline \multicolumn{7}{|c|}{ Mar 1979 - Feb 1987} \\
\hline Sterling & 0.00 & 0.53 & 0.51 & 0.05 & $6.15^{*}$ & $0.08 *$ \\
\hline Deutsche Mark & NA & NA & NA & NA & NA & NA \\
\hline Dollar & NA & NA & NA & NA & NA & NA \\
\hline Argentine Peso & NA & NA & NA & NA & NA & NA \\
\hline \multicolumn{7}{|c|}{ Mar. 1987 - Sept. 1993} \\
\hline Sterling & 0.00 & 0.46 & 0.37 & $-1.37^{*}$ & 28.45 & $0.10^{*}$ \\
\hline Deutsche Mark & -0.01 & 0.27 & 0.05 & $-20.17 *$ & $574.98 *$ & $0.30^{*}$ \\
\hline Dollar & 0.00 & 0.78 & 0.72 & $-0.96 *$ & $11.57 *$ & $0.09 *$ \\
\hline Argentine Peso & -0.52 & 4.13 & 0.89 & $-7.40 *$ & $133.17^{*}$ & $0.30 *$ \\
\hline \multicolumn{7}{|c|}{ Oct. 1993 - Dec. 1998} \\
\hline Sterling & -0.01 & 0.36 & 0.34 & -0.09 & $3.47 *$ & $0.07 *$ \\
\hline Deutsche Mark & 0.00 & 0.40 & 0.37 & $-0.38^{*}$ & $4.56^{*}$ & $0.11 *$ \\
\hline Dollar & 0.00 & 0.54 & 0.57 & $-0.22 *$ & $2.64 *$ & $0.05 *$ \\
\hline Argentine Peso & -0.01 & 0.55 & 0.58 & $-0.27 *$ & $2.61 *$ & $0.05 *$ \\
\hline
\end{tabular}

Notes: All exchange rates are in terms of one unit of an Irish Pound with the exception of the Euro which is quoted in Dollars. Normality is tested using the Kolmogorov-Smirnov statistic. The critical values for the skewness, kurtosis and normality tests is zero. The symbol $*$ indicates significance at the five percent level. Mean, standard deviation, range and interquartile range measures are presented in percentage form.

Turning next to the most commonly cited volatility measure, the unconditional standard deviation, we see that this value is quite substantial for the euro with average values in excess of 0.5 percent. Again this value is in excess of that experienced by the pound-sterling rate. We can see that those currencies with a more rigid relationship, for example, the mark had relatively low average levels of volatility vis-à-vis floating currencies. In addition, we also note that there is in general an overall reduction in volatility over the lifetime of the EMS as demonstrated by this measure.

To summarise, it should be clear from the above analysis that the euro conforms to the characteristics of other currencies. The returns are non-normal, non-symmetric and are leptokurtotic. In addition, the initial signals of volatility indicate a currency that is greater than anything experienced by the pound-sterling rate during the last 
twenty years. Further analysis through the determination of conditional volatility with a GARCH process, and the impact of large exchange rate changes using Extreme Value Theory, will give us a greater overview of the risk profile of the euro.

\section{CONDITIONAL VOLATILITY ESTIMATES}

Following on from our initial analysis, this section focuses more narrowly in determining the comparative levels of volatility inherent in currencies past and present facing Irish economic agents. To aid brevity, all other currencies with the exception of sterling and the euro are hereafter ignored. Sterling is included to illustrate the comparative volatility for Ireland's main trading partner during the last two decades. Three areas related to conditional volatility estimates are examined. First, the conditional variance of the series' is measured using a GARCH $(1,1)$ process. This is followed by a graphical representation of the conditional second moments. Finally, a comparative analysis of the variances' descriptive statistics allows us to further infer on the extent of volatility that is inherent in the currencies.

The estimates of the GARCH $(1,1)$ model are presented for the exchange rate series in Table 5. The parameters appear to be well specified for each series. From these coefficents, estimates of conditional variance are determined and these are plotted in Figures 3 to 6 . Focusing on the euro series, we can first see the time-varying characteristic of the short-run volatility. It appears that these fluctuations resulted in peaks around September 1997, September 1998 and July 1999, although daily individual exchange rate changes are reasonably small. ${ }^{18}$

Table 5: GARCH $(1,1)$ Models for Daily Exchange Rate Returns Series

\begin{tabular}{lrrrr}
\hline & Euro & \multicolumn{1}{c}{ Sterling } & \multicolumn{1}{c}{ Sterling } \\
$(\mathbf{1 9 7 9 - 1 9 8 7 )}$ & $(\mathbf{1 9 8 7 - 1 9 9 3 )}$ & $\begin{array}{c}\text { Sterling } \\
(\mathbf{1 9 9 3 - 1 9 9 9 )}\end{array}$ \\
\hline$\alpha_{0}$ & 0.00 & 0.00 & 0.00 & 0.00 \\
& $(1.38)$ & $(7.40)$ & $(12.25)$ & $(1.58)$ \\
$\alpha_{1}$ & 0.04 & 0.16 & 0.10 & 0.05 \\
& $(2.33)$ & $(9.68)$ & $(12.84)$ & $(7.75)$ \\
$\beta_{1}$ & 0.91 & 0.77 & 0.90 & 0.95 \\
& $(20.10)$ & $(32.49)$ & $(140.44)$ & $(154.82)$ \\
Iterations & 9 & 8 & 20 & 9 \\
Log Likelihood & 2380.98 & 8029.72 & 7056.39 & 6982.49 \\
\hline
\end{tabular}

Note: T-statistics are in parentheses.

The determination of the comparatively greatest conditional volatility is formally examined in Table 6 where some descriptive statistics are presented. We see here that the conditional volatility for sterling generally reduced during the lifetime of its membership of the EMS. However, it is clear that the average volatility of the euro (.0035) outweighs that of the other series analysed. Focusing on the percentiles we 
can see the pattern of risk values at different quantiles.

Up to the seventy-fifth percentile, the euro volatility outweighs the others series, whereas thereafter this is reversed with the exception of sterling between 1993 and 1999. This points out an important characteristic of the volatility estimates, namely, that while the average variance estimate for the euro is larger than other exchange rate series, their tail values are much smaller than sterling's in the time frame before the widening of the EMS bands in 1993. As these tail values are of major importance to any economic agent who is exposed to them, this suggests that a more detailed analysis of the tail estimates of currency movements would be advantageous by providing information on the dangers caused by these large fluctuations.

Table 6: Mean and Percentiles for Conditional Volatility Estimates of Exchange Rate Returns Series'

\begin{tabular}{lcccccc}
\hline Currency & Mean & \multicolumn{5}{c}{ Percentiles } \\
\hline & & $\mathbf{5}$ & $\mathbf{2 5}$ & $\mathbf{5 0}$ & $\mathbf{7 5}$ & $\mathbf{9 5}$ \\
\cline { 3 - 7 } Euro & 0.0035 & 0.0025 & 0.0028 & 0.0033 & 0.0038 & 0.0050 \\
Sterling (1979-1987) & 0.0029 & 0.0012 & 0.0016 & 0.0022 & 0.0033 & 0.0066 \\
Sterling (1987-1993) & 0.0023 & 0.0006 & 0.0009 & 0.0015 & 0.0022 & 0.0069 \\
Sterling (1993-1998) & 0.0012 & 0.0002 & 0.0003 & 0.0008 & 0.0019 & 0.0036 \\
\hline
\end{tabular}

Note: Measures are presented in percentage form.

Figure 3: Conditional Variance for Euro-Dollar Series

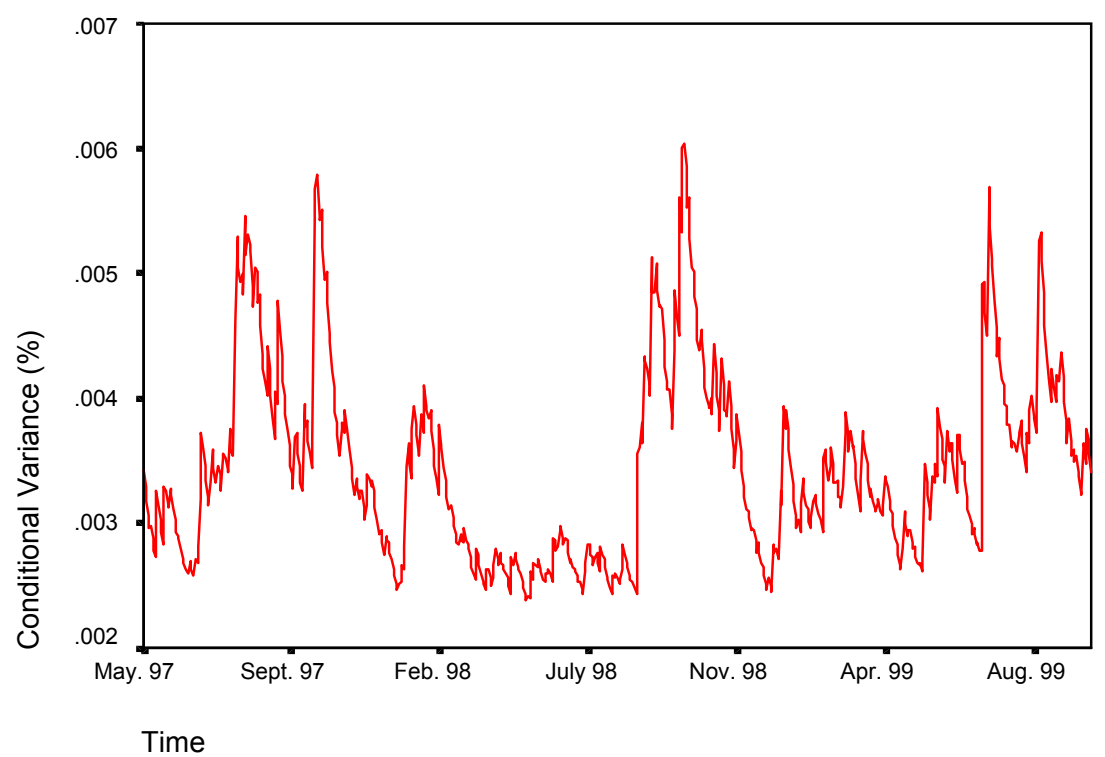


Figure 4: Conditional Variance for Punt-Sterling Series (1979-1987)

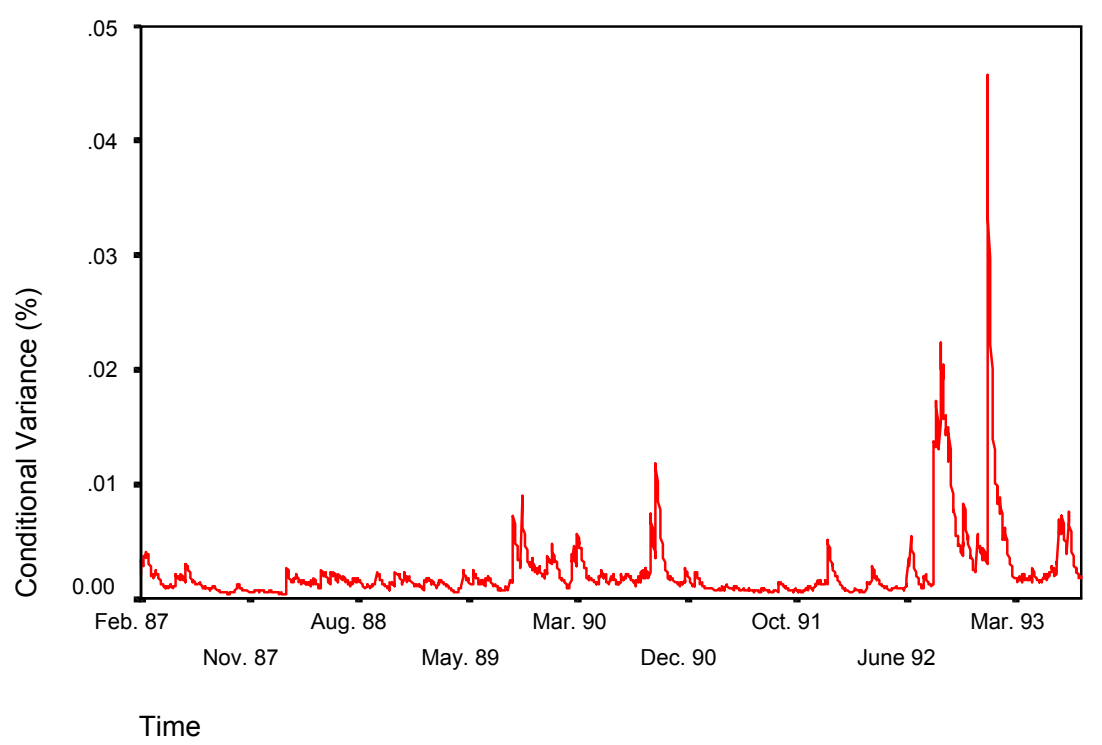

Figure 5: Conditional Variance for Punt-Sterling Series (1987-1993)

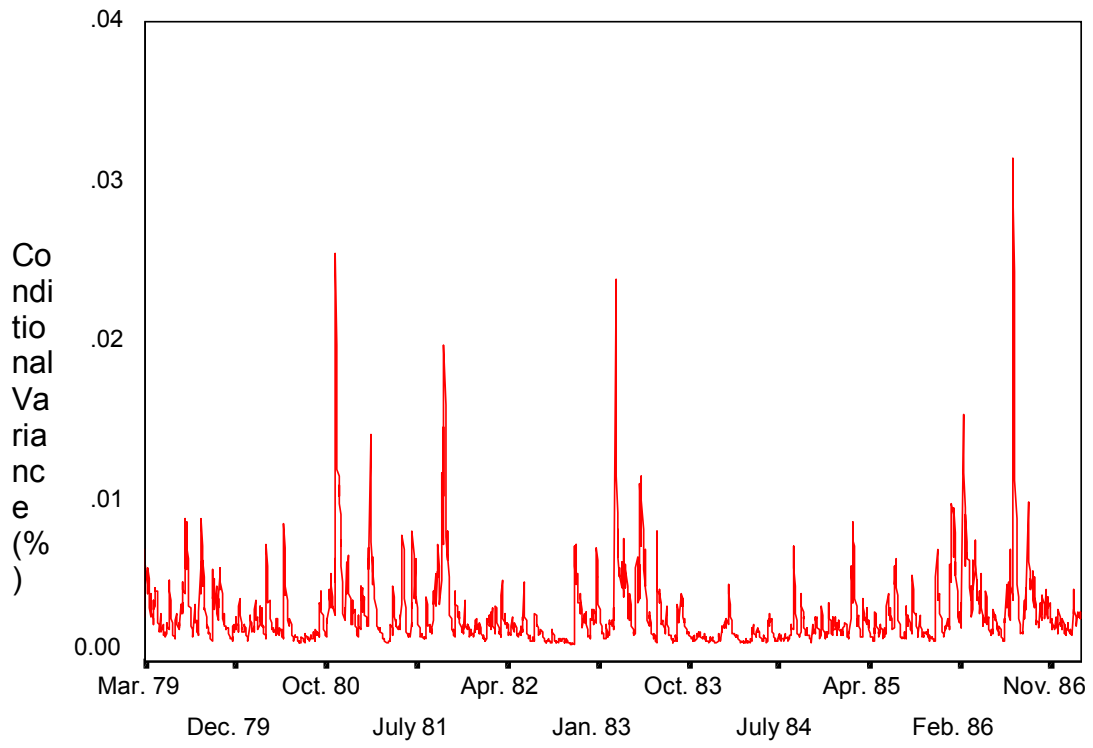

Time 
Figure 6: Conditional Variance for Punt-Sterling Series (1993-1998)

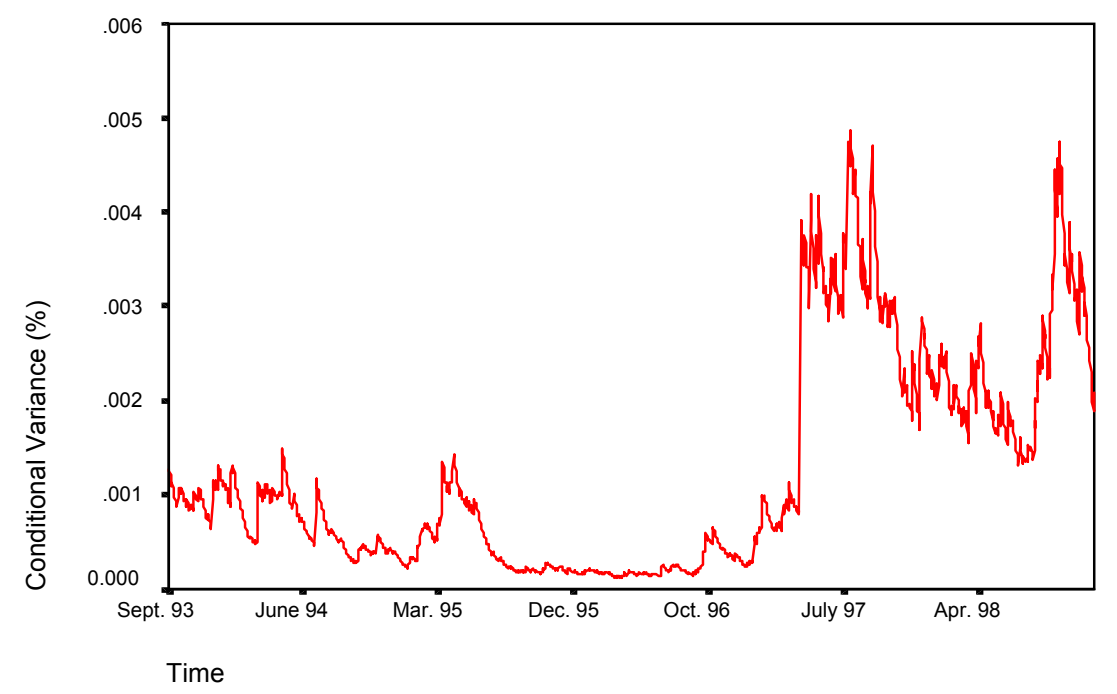

8. EXTREME VALUE ESTIMATES

The Extreme Value measure, the excess probability estimate, $\mathrm{P}_{\mathrm{r}}$, deals with the issue of having exchange rate fluctuations in excess of a certain percentage. In Table 7, we see that the probability of having an exchange rate change in excess of 10 percent to be very low, for example, 0.0008 in the case of the Euro. As we would expect a priori, the probability of exceeding a certain value increases as you move to smaller fluctuation levels.

Table 7: Tail Excess Probability Estimates for Exchange Rate Returns Series

\begin{tabular}{lllllll}
\hline Contract & $\mathbf{P}_{\mathbf{r}} \mathbf{1 0 \%}$ & $\mathbf{P}_{\mathbf{r}} \mathbf{8 \%}$ & $\mathbf{P}_{\mathbf{r}} \mathbf{5 \%}$ & $\mathbf{P}_{\mathbf{r}} \mathbf{3 \%}$ & $\mathbf{P}_{\mathbf{r}} \mathbf{1 \%}$ & $\mathbf{P}_{\mathbf{r}} \mathbf{0 . 5 \%}$ \\
\hline Euro & 0.0008 & 0.0020 & 0.0132 & 0.1040 & 8.8049 & 144.8392 \\
Sterling (79-87) & 0.0018 & 0.0037 & 0.0164 & 0.0826 & 2.6882 & 24.1949 \\
Sterling (87-93) & 0.0099 & 0.0174 & 0.0573 & 0.2099 & 3.4190 & 19.8848 \\
Sterling (93-98) & 0.0004 & 0.0010 & 0.0054 & 0.0343 & 1.8310 & 22.5126 \\
\hline
\end{tabular}

Notes: $\mathrm{P}_{\mathrm{r}} 10 \%, \mathrm{P}_{\mathrm{r}} 8 \%, \mathrm{P}_{\mathrm{r}} 5 \%, \mathrm{P}_{\mathrm{r}} 3 \%, \mathrm{P}_{\mathrm{r}} 1 \%$, and $\mathrm{P}_{\mathrm{r}} 0.5 \%$ represent the probability of an exchange rate movement being in excess of the associated percentages. The excess probability estimates are presented in percentage form.

The information in Table 7 can be used to make decisions on the basis of statistical inference. Whilst, much of the creation of the euro was down to political decision making, we can now make some comments about the euro that are based on the statistical evidence of extreme volatility levels. First, the probability of having the 
very large exchange rate changes in Table 7 are more likely for the sterling rate between 1979 and 1993 than the euro. Second, for comparatively smaller currency fluctuations, the probability of these occurring is larger for the euro than that of sterling.

Thus it can be seen that the euro has more characteristics of a floating currency than the pound-sterling rate. These attributes include having an average volatility level that is comparatively large, and also, extreme rate changes located in the tail of a distribution being reasonably smooth. In contrast, the pound-sterling rate always had the possibility of government intervention in the case of very turbulent times. This occurred through the Irish authorities informal tracking of sterling during the first sub-period of analysis, or through sterling tracking the mark (and as a consequence, tracking all ERM currencies) during the second sub-period. Government intervention would take place to support a currency, and speculators at certain times saw this as an opportunity to test the resources of the respective central banks. For example, in the case of the EMS currency crises, the extreme volatility in the market was caused by massive speculative activity that was being fought against by the authorities of the participating members.

This brings us to another but related issue. Namely are there any levels of fluctuations seen to be so large, that the authorities would not tolerate their continuation and so leading to an abandonment of the system. Remember the UK opted out of the ERM after speculative activity against sterling became so intense, that the monetary authorities felt that the case of maintaining the currency's value within the predefined bands was no longer worth it. In Table 7, we can see that given the extreme volatility levels inherent in the euro, the Irish government would be reasonably unperturbed by this issue. This is due to the probability of very large rate movements occurring being more likely with Ireland's previous relationship with sterling than with the euro.

However, more worrying for the euro, is its propensity to make reasonably small, but economically important, fluctuations. We can see in Table 7 that the probability of having an exchange rate change in excess of 0.5 percent is more likely for the euro that the experience of the pound-sterling. This issue is very relevant at the moment with sterling tracking the dollar, and given the extent of the extent of Ireland's trade dependence with the non-Euro area as described in Table 2. This Irish experience of the euro may be looked back on in the future as one that provided stability from extreme currency fluctuations, but also one where they suffered a reasonably high level of constant volatility with their main trading partners. 


\section{Endnotes}

1. The terms volatility, fluctuations and risk have a similar meaning and they are interchanged for each other in this paper.

2. The 'peso problem' has been adopted as metaphor in the Extreme Value literature to describe a situation that will rarely happen (very low probability) but of costly consequences (very large losses).

3. One can go further and say that large financial market volatility, including exchange rate instability, can have a knock on effect on other economic variables in that economy and also impact other economies. A clear example of this contagion is the fallout from the Asian crises that has rippled through the world economy in 1997/98.

4. This currency was a weighted basket of European currencies, including the UK who did not join the EMS until 1990. The Irish pound's initial weighting in the ECU on entry to the EMS was 1.1 percent.

5. As this paper shows, failure of such a dual tracking policy is to be expected given the volatility that is inherent in bilateral exchange rates.

6. As yet, the UK has not formally declared whether they will join. In general commentators believe that membership will occur, but for the purposes of this paper, I assume that they will only agree to participation in the scheme from the time that they actually make this declaration. Given this context, the eurosterling fluctuations are currently important in terms of trade because of Ireland's strong connections with the UK, but also in a political way in terms of North/South economic co-operation.

7. Firms rather than individuals are usually cited for applying these methods.

8. As a consequence, the benefit of removing these distortions is also difficult to compute.

9. See Temperton (1993) and Corsetti et al. (1998) for the respective discussions on the EMS and Asian crises.

10. The second moment refers to the standard deviation dispersion statistic of a distribution of exchange rate changes.

11. A comprehensive review of GARCH related models can be found in Pagan (1996).

12. The central limit theorem is used it this context as well as in general, to demonstrate that when the sample size of a variable under analysis gets very large it converges to the properties of a normal distribution.

13. Weak convergence is only assumed so the relationship between the series of exchange rates and the max-stable distributions is semi-parametric in nature.

14. All data was provided by DataStream.

15. It is debatable as to whether the pound's closer relationship with the mark was a result of a conscious effort by Irish authorities, or actually caused by sterling's formal tracking of the German currency after 1987.

16. Kurtosis is a combination measure of peakedness around the mean and magnitude around the tail. 
17. Leptokurtosis occurs when they are too many exchange rate changes located around the mean and tail of a distribution relative to a normal distribution.

18. It is not possible to compare the magnitude of exchange rate volatility at this juncture as they are drawn to different scale. Attempts to have a common vertical axis for the plots in Figures 3-6 were unsuccessful due to the large extreme values for the sterling rate in the time-period between March 1979 and September 1993.

19. A max-stable distribution is different to be the stable distribution examined in Cotter (1998) which has the property that it has a characteristic exponent that remains unchanged across different sums of observations. 


\section{References}

Bartolini, L. and A. Prati, 1999. "Soft Exchange Rate Bands and Speculative Attacks: Theory, and Evidence from the ERM since August 1993", Journal of International Economics, Vol. 49, pp. 1-29.

Bollerslev, T., 1986. "Generalised Autoregressive Conditional Heteroskedasticity", Journal of Econometrics, Vol. 31, pp. 307-327.

Corsetti, G., P. Pesenti, and N. Roubini, 1998. "What Caused the Asian Currency and Financial Crises", mimeo, New York University.

Cotter, J. 1998. "Testing Distributional Models for the Irish Equity Market", Economic and Social Review, Vol. 29, pp. 257-269.

Cotter, J. 1999. "Extremal Behaviour and Value at Risk Measures for the Irish Equity Market", Paper presented at the Irish Economic Association's Annual Conference, Westport.

Diebold, F. X., 1988. Empirical Modelling of Exchange Rate Dynamics, Springer Verlag, New York.

Engle, R. F., 1982. "Autoregressive Conditional Heteroskedasticity with Estimates of the Variance of UK Inflation”, Econometrica, Vol. 50, pp. 987-1008.

European Economy, 1990. One Market, One Money: An Evaluation of the Potential Benefits and Costs of Forming an Economic and Monetary Union, No. 44.

EUROSTAT, 2000. External and Intra European Union Trade - Statistical Yearbook, Eurostat, Luxembourg.

Feller, W., 1971. An Introduction to Probability Theory and its Applications, John Wiley, New York.

Flood, R. and A. Rose, 1995. "Fixing Exchange Rates: A Virtual Quest for Fundamentals", Journal of Monetary Economics, Vol. 36, pp. 3-37.

Flood, R. and A. Rose, 1998. "Understanding Exchange Rate Volatility", mimeo, University of California at Berkeley.

Greenspan, A., 1997. "Maintaining Financial Stability in a Global Economy", Discussion at Federal Reserve Bank of Kansas City Symposium.

Hall, P., 1982. "On some simple Estimates of an Exponent of Regular Variation", Journal of the Royal Statistical Society, Series B, Vol. 44, pp. 37-42. 
Hill, B. M., 1975. "A Simple General Approach to Inference about the Tail of a Distribution”, Annals of Statistics, Vol. 3, 1163-1174.

Hols, M. C. A. B. and C. De Vries, 1991. "The Limiting Distribution of Extremal Exchange Rates Returns", Journal of Applied Econometrics, Vol. 6, 287-302.

Honohan, P. and P. R. Lane, 1999. "Pegging to the Dollar and the Euro", International Finance, No. 2, pp. 379-410.

IMF, 1993. World Economic Outlook, International Monetary Fund, October.

Kearns, P. and A. Pagan, 1997. "Estimating the Density Tail Index for Financial Time Series", The Review of Economics and Statistics, Vol. 79, pp 171-175.

Koedijk, K. G. and C. J. M. Kool, 1994. "Tail Estimates and the EMS Target Zone", Review of International Economics, Vol. 2., 153-165.

Leadbetter, M. R., G. Lindgren and H. Rootzen, 1983. Extremes and Related Properties of Random Sequences and Processes, Springer, New York.

Leddin, A. and J. O' Leary, 1995. "Fiscal, Monetary and Exchange Rate Policy" in Chapter 6 of J.O'Hagan (ed.) The Economy of Ireland, Gill and MacMillan.

Levich, R. M., 1985. "Empirical Studies of Exchange Rates: Price Behaviour, Rate Determination and Market Efficiency", Handbook of International Economics, Vol. 2, pp. 979-1040.

Obstfeld, M., 1994. "Risk-Taking, Global Diversification and Growth", American Economic Review, Vol. 84, pp. 1310-29.

Pagan, A., 1996. "The Econometrics of Financial Markets”, Journal of Empirical Finance, Vol. 3, pp. 15-102.

Phillips, P. C. B., J. W. McFarland and P. C. McMahon, 1996. "Robust Tests of Forward Exchange Market Efficiency with Empirical Evidence from the 1920s", Journal of Applied Econometrics, Vol. 11, pp. 1 - 22.

Power, J., 1999. “Obituary for the Irish Pound”, Irish Banking Review, pp. 12-23, Summer.

Sachs, J. M. and A. M. Warner, 1995. "Economic Reform and the Process of Global Integration", Brookings Papers on Economic Activity, Vol. 1, pp. 1-118.

Temperton, P. (ed.), 1993. The European Currency Crises. Cambridge: Probus. 


\section{APPENDIX A: ARCH and GARCH Processes}

Engle's (1982) ARCH (q) model is outlined in (A1) - (A3) where q is the number of lags. Two sequences $\{\mathrm{Yt}\}$ and $\{\mathrm{Zt}\}$ are related by the regression equation (A1). The distribution of the disturbance term is assumed normal with zero mean and conditional variance $\delta_{\mathrm{t}}$ as in (A2). The conditional variance is modelled in (A3).

$$
\begin{aligned}
& \mathbf{Y}_{\mathbf{t}}=\mathbf{b Z} \mathbf{Z}_{\mathrm{t}}+\varepsilon_{\mathrm{t}} \\
& \varepsilon_{\mathrm{t}} \mid \mathbf{I}_{\mathrm{t}-1} \sim \mathbf{N}\left(\mathbf{0}, \delta_{\mathrm{t}}\right) \\
& \delta_{\mathrm{t}}=\alpha_{0}+\sum \alpha_{\mathrm{i}} \varepsilon_{\mathrm{t}-\mathrm{i}}^{2}
\end{aligned}
$$

where $I_{t-1}$ is the information set at time $t-1$, and $\delta_{t}$ is the conditional variance of the disturbance term, $\varepsilon_{t}$. Volatility is time-varying and modelled on past squared values of the disturbance term.

Empirically the lag structure, $\mathrm{q}$, has been found to be large. A more parsimonious modelling procedure is presented by Bollerslev's (1986) GARCH (p, q) process. By again using (A1) as the relationship between the sequences $\{\mathrm{Yt}\}$ and $\{\mathrm{Zt}\}$, the disturbance term is shown to have conditional variance $h_{t}$ in (A4), and it is modelled by a GARCH process of order ( $p, q$ ), given in (A5).

$$
\begin{aligned}
& \varepsilon_{\mathbf{t}} \mid \mathbf{I}_{\mathbf{t}-\mathbf{1}} \sim \mathbf{N}\left(\mathbf{0}, \mathbf{h}_{\mathbf{t}}\right) \\
& \mathbf{h}_{\mathbf{t}}=\alpha_{\mathbf{0}}+\sum \alpha_{\mathrm{i}} \varepsilon_{\mathbf{t}-\mathbf{i}}^{2}+\sum \beta_{\mathbf{j}} \mathbf{h}_{\mathbf{t}-\mathbf{j}}^{2}
\end{aligned}
$$

Bollersev's extension of the ARCH model allows the conditional variance term, $h_{t}$ be defined as an ARMA process. If $p=0$, (A5) is equivalent to (A3). The conventional starting point, and generally supported specification for most speculative time series is the $\operatorname{GARCH}(1,1)$, where $p=q=1$. If $p=q=0$, there is no heteroskedasticity present, and conditional and unconditional volatility are constant. 


\section{APPENDIX B: Extreme Value Theory}

Taking a sequence of stationary exchange rate changes $\left\{\mathrm{R}_{1}, \mathrm{R}_{2}, \ldots, \mathrm{R}_{\mathrm{n}}\right\}$ that may, but not necessarily be identical and independently distributed (Leadbetter et al, 1983), and that has a distribution function $\mathrm{F}$. This sequence is expressed in terms of the probability of minimum exchange rate changes being below a certain value, where

$$
\mathbf{M}_{\mathbf{n}}=\min \left\{\mathbf{R}_{1}, \mathbf{R}_{2}, \ldots, \mathbf{R}_{\mathbf{n}}\right\}
$$

and

$$
\mathbf{P}\left\{\mathbf{M}_{\mathbf{n}} \leq \mathbf{r}\right\}=\mathbf{F}^{\mathbf{n}}(\mathbf{r})
$$

where $M_{n}$ is an order statistic that determines the maximum of the sequence of $n$ returns with a probability of $\mathrm{F}^{\mathrm{n}}(\mathrm{r})$ of falling below a certain value, $\mathrm{r}$.

This expression deals with the downside risk inherent in exchange rate movements as indicated in Figure 1.

Assuming, that the distribution of $\mathrm{F}$ converges at the limit to a distribution $\mathrm{G}$, this limiting distribution can take on three forms (Hols and DeVries, 1991). This distribution $\mathrm{G}$ referred to as max-stable ${ }^{19}$ adheres to the following types:

$$
\begin{aligned}
& \text { Type I: } \quad \text { G(r) } \quad=\exp \left(-\mathbf{e}^{-\mathbf{r}}\right) \quad-\infty<\mathbf{r}<\infty
\end{aligned}
$$

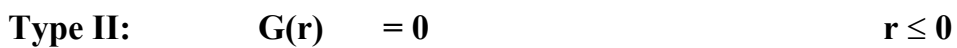

$$
\begin{aligned}
& =\exp (-r)^{(-1 / \alpha)}=\exp (-r)^{-\gamma} \quad r>0 \\
& \text { Type III: } \quad \begin{array}{lll}
\text { G(r) } & =\exp \left(-(-\mathbf{r})^{(-1 / \alpha)}\right)=\exp \left(-(-\mathbf{r})^{-\gamma}\right. & \mathbf{r}<0 \\
& =1 & \mathbf{r} \geq 0
\end{array}
\end{aligned}
$$

where $\gamma$ is the value of the tail index and $\alpha$ is its inverse, that is, $\gamma=1 / \alpha$.

The three types of converging distributions can be distinguished by their respective tail behaviour. Type I refers to a case where the tail declines exponentially and all moments of the distribution are finite. Type III refers to a case where the tail is bounded. Type II follows the characteristics of a power decline in the tail causing a relatively slow decay for convergence towards the limit, vis-à-vis the exponential decline of the Type I process. For this Type II max-stable process, the relatively slow decline represents a fat tail situation, and in this case, all the moments are not finite. Given the finding that exchange rate first differences exhibit fat tails, the distribution $\mathrm{G}$ takes on only one possible form: 


$$
\begin{aligned}
& \mathbf{G}(\mathbf{r})=\mathbf{0} \quad \mathbf{r} \leq \mathbf{0} \\
& =\quad \exp (-r)^{(-1 / \alpha)}=\exp (-r)^{-\gamma}, \quad \quad r>0
\end{aligned}
$$

Equation (B4) indicates that for fat tailed distributions, an estimate of the tail index, $\gamma$ is used to give extreme risk measures.

The only sufficient property for the fat-tailed distribution to hold is that the data has a regular variation at infinity property (Feller, 1971), and is given as:

$$
\lim _{t \rightarrow \infty} \frac{1-\mathbf{F}(\mathbf{t r})}{1-\mathbf{F}(\mathbf{t})}=\mathbf{r}^{-\gamma}
$$

The semi-parametric Hill (1975) estimator, $\gamma$, based on order statistics is used to determine the tail density coefficient:

$\gamma=1 / \alpha=(1 / m) \sum\left[\log \mathbf{r}_{(n+1-i)}-\log \mathbf{r}_{(n-m)}\right] \quad$ for $\mathbf{i}=1 \ldots . m$

This tail estimator is asymptotically normal, $(\gamma-\mathrm{E}\{\gamma\}) /(\mathrm{m})^{1 / 2} \approx\left(0, \gamma^{2}\right)$ (Hall, 1982). This estimation takes a cut-off point, $m$, which has an exchange rate return, $r_{(n-m)}$, that we want to compare all other currency movements against. Then a summation of differences between all exchange rate changes to the left of $m$ (assuming analysis of downside risk) and at $\mathrm{m}$ itself is calculated. This is then averaged by dividing by $\mathrm{m}$ giving a measure of dispersion located at this area of the distribution.

An empirical issue in the application of Extreme Value measures is the optimal number of exchange rate changes entailed in the tail of a distribution. The approach adopted here in determining the optimal tail threshold value was developed by Hall (1982) and updated by Phillips et al. (1996). The optimal threshold value, $\mathrm{M}_{\mathrm{n}}$, which minimises the mean square error of the tail estimate, $\gamma$, is $m=M_{n}=\left\{\lambda n^{2 / 3}\right\}$ where $\lambda$ is estimated adaptively by $\lambda=\mid \gamma_{1} / 2^{1 / 2}\left(\mathrm{n} /\left.\mathrm{m}_{2}\left(\gamma_{1}-\gamma_{2}\right)\right|^{2 / 3}\right.$. The preliminary estimates of $\gamma_{1}$ and $\gamma_{2}$ are obtained using (B6) with data truncations $\mathrm{m}_{1}=\mathrm{n}^{\sigma}$ and $\mathrm{m}_{2}$ $=\mathrm{n}^{v}$. Phillips et al. (1996) suggest using $\sigma=0.6$ and $v=0.9$ as the values of $\mathrm{m}$ and $\gamma_{1}$ are insensitive to the choice of $\sigma$ and $v$ for small intervals around these estimates.

Using (B6) to determine the tail index, the tail excess probability calculation is then based on the following:

$$
\mathbf{P}_{\mathrm{r}}=\left(\mathrm{r}_{\mathrm{M}, \mathrm{n}} / \mathbf{r}_{\mathrm{p}}\right)^{1 / / \gamma} \mathbf{M} / \mathbf{n}
$$




\section{DISCUSSION}

Mr. Jim Power: I would like to thank John Cotter for this most interesting and stimulating paper which should prove a useful analytical tool for those domestic agents who are currently struggling with the vagaries and unpredictability of the euro. Given that I work in a commercial environment where currencies are traded and where corporate treasurers constantly seek guidance and advice on exchange rate movements, I will in the main restrict my comments to these issues rather than seeking to comment on the validity of the statistical procedures employed by the speaker.

From the perspective of exchange rate forecasters and corporate treasury managers, the first year of the euro has turned out to be a relatively difficult experience. In hindsight, this should not come as a surprise as the creation of a single currency out of eleven different currencies was always going to be an unpredictable and potentially difficult task. For Ireland, the problems have been exaggerated by the failure of sterling to participate. As the paper points out, Ireland has had problems with sterling since the decision in 1979 to join the Exchange Rate Mechanism (ERM) of the European Monetary System without the currency of its major trading partner.

The Irish authorities were forced to unilaterally devalue the Irish pound within the ERM on two occasions during the 1980's, and on one occasion in the 1990s. Furthermore, the Irish authorities had to revalue the Irish pound in the year leading up to the launch of the single European currency, thereby becoming the first currency to be formally revalued against the Deutschmark. All of these currency adjustments were primarily driven by the behaviour of sterling. For example the 10 percent devaluation of January 1993 was a result of sterling leaving the ERM and its subsequent sharp depreciation. Then in March 1998, the Irish pound was revalued by 3 percent due to the strength of sterling.

Extreme sterling moves in either direction prove problematical for Irish companies and the economy in general. It is stated in the paper that between 1987 and 1992 exchange rate stability for the Irish pound was guaranteed. This is true, but only because sterling behaved itself. Joining EMU without the currency of its major trading partner, the UK, which now accounts for 23 percent of its exports and one third of its imports, always had the potential to create problems for Ireland.

Expectations for the euro in January 1999 were very positive and ultimately very incorrect. It depreciated steadily during 1999 and in the early months of 2000, it has struggled under parity against the dollar and almost 9 percent below its highs against sterling. Firstly, the euro's performance since its launch has been influenced by the relative economic performance of the euro area and the US. Euro area growth turned out considerably weaker than expected, while US growth surpassed the most optimistic expectations. This was not a development that most forecasters 
expected. Secondly, there was a belief that the euro would benefit from structural factors, such as a switch in global reserves away from the dollar towards the euro. This did not materialise. Overriding these two factors, was the fact that in the first ten months of 1999, direct and portfolio investment net outflows totalled US\$ 149 billion, compared to a current account surplus of US\$ 38 billion. Global investors bought the US "new economy" story and shunned the "European model". Structural rigidities in Europe's labour market, the lack of a services sector culture and a failure to match the US in terms of new technology development, have all combined to boost capital flows out of the Euro zone.

Forecasting sterling has never been an easy task, but based on past experience it was possible to be reasonably confident at the launch of EMU that sterling would continue to have a volatile relationship with the basket of Euro zone currencies. This is indeed what has transpired. Sterling has been quite volatile against the euro since its launch, but its trend has not been in the direction that most forecasters expected. Sterling has appreciated sharply against the euro, due mainly to the strong dollar and substantially higher interest rates in the UK compared to Europe.

This exchange rate volatility of the euro against sterling has posed considerable difficulties for Irish companies exposed to the UK market. The paper cites the two commonly used arguments to negate the hypothesis that the remaining exchange rate costs between Euro zone members and non members is a problem. Firstly, it is argued that the availability of hedging products would allow the elimination or diversification of exchange rate risks, and that their popularity suggests that these are perceived to be successful in reducing exchange rate risk. Secondly it is argued that importers can shift their purchasing pattern away from markets involving volatile currency movements. Both of these arguments are open to dispute.

The experience of Irish corporate agents since the launch of the euro has not been good. When the euro was launched there was a solid consensus in financial markets that it would appreciate against the dollar and sterling due to a range of cyclical and structural factors. Believing this to be a realistic outcome, many Irish companies with dollar and sterling receivables sold the two currencies forward to guard against such currency movements.

In February 1999 it was possible to sell sterling forward for one year at 89.62 pence, comprising of the spot rate at the time of 87.82 pence plus 180 forward points. At the same time it was possible to sell the dollar forward for the same period at a rate of 1.4631, comprising of the spot rate of 1.4329 plus 302 forward points. Many companies took this option. Unfortunately for those companies, the market predictions were totally wrong. Today, the sterling rate against the Irish pound is 78.25 pence, and the dollar rate against the Irish pound is 1.25.

This hedging strategy resulted in a considerable profit foregone or opportunity cost. Likewise, importers with a requirement to buy sterling and the dollar believed the 
market consensus and did not buy the currency forward, which in hindsight would have been the correct strategy. Those companies that did sell forward have missed out on a very strong currency move that would have benefited profits significantly, while those that failed to buy forward are now suffering financial loss.

However, a hedging decision is normally taken to ensure certainty of cash flow in the domestic currency, rather than to speculate on a future currency movement. The bottom line is that hedging is not the solution to all problems and can prove extremely costly. On the second argument, it is not always possible to change the source of imports to avail of exchange rate certainty. For many importers from the UK, business relationships have often been long established and a level of confidence in the product has been formed. It is not an easy decision to turn one's back on these considerations and at the very least, it can take some time to find new sources and establish new relationships.

The paper mentions the traditional view on exchange rate volatility, namely that it reduces economic growth. It is argued that volatility reduces investment, forces firms to set high prices in an attempt to satisfy their risk averse nature, and imposes expensive search costs on economic agents. There is ample historical empirical evidence to back up these contentions, but in today's environment there is little evidence to suggest that exchange rate volatility is forcing firms to set higher prices. Greater price transparency resulting from EMU, growing competition in the goods markets and globalisation have combined to undermine traditional economic models. It has been asserted in the past that the key determinant of Irish inflation is the level of inflation in the UK and the exchange rate value between the Irish pound and sterling. Theory would suggest that the decline of the Irish pound against sterling, of almost 15 percent in just over a year, would have resulted in a sharp increase in Irish inflation. Inflation has more than doubled in twelve months, but this has little to do with the value of the Irish pound.

The consumer price index for Ireland shows that in the year to January 2000, the price of items such as clothing and footwear and durable household goods has actually declined. Goods prices are subject to the competitive forces inherent in "new economy" thinking. Inflation is coming through on the services' side of the Irish economy, where exchange rates are largely irrelevant. Nevertheless, the fall in the Irish pound against sterling and its failure to follow through to inflation suggests that importers are either changing their geographical source of goods or are facing tighter profit margins. Trading patterns between Northern Ireland and the Republic are changing as a result of currency movements. This will remain an issue for the greater economic integration of the island of Ireland, for as long as sterling remains outside the euro area.

The overall conclusions of the paper are very interesting for Irish economic agents with an exposure to non-euro currencies such as sterling and the dollar. Exchange rate behaviour is not characterised by a normal distribution and frequently displays a 
"fat tailed" characteristic. The use of Extreme Value Theory should enable exposed parties to assess more accurately future likely volatility and to act accordingly to minimise the risk. Ireland as part of the euro is clearly vulnerable from the point of view that the euro has more characteristics of a floating currency than the Irish pound-sterling rate has had in the past. This implies that the Irish pound as part of the euro will be subject to greater average volatility against sterling.

The fixed rate system that Ireland is now involved in with the other members of the euro is not likely to result in the chaotic outcome that characterised previous fixed exchange rate regimes, unless of course the fundamentals underlying the system become seriously skewed. The markets attach a low probability to such an outcome as evidenced by the fact that long-term interest rates across the euro zone countries are all trading within 50 basis points of Germany. This is a vote of confidence.

One cannot, however, but hanker for the period of 15 percent bands of fluctuation within the ERM, when the Irish pound had the scope to maintain fundamentally competitive levels against sterling and the Deutschemark. Such a state of bliss is unlikely to recur until sterling joins EMU. I second the vote of thanks for a stimulating paper.

Mr. Aidan Meyler: In common with the discussant I would like to thank the speaker for an interesting paper. I do, however, have four comments I wish to make on the paper. First, Figure 2 illustrates a normal and a fat-tailed distribution. However, exchange rate changes, in common with other economic series such as share prices, as well as having fatter tails also exhibit a higher peak in the centre of the distribution than the normal distribution. In other words, relatively small movements around the mean are more frequent than would be expected if the distribution was normal. Updating Figure 2 to reflect this would be useful.

Second, I am concerned by the use of euro futures data prior to January 1999. While being aware of the author's need for sufficient data points, I feel that using futures data poses two possible problems: (i) interest rate movements and changes in interest rate expectations will impact on futures and (ii) prior to January 1999, the euro, as an entity was not focused on by the markets. Indeed, as the composition of the euro was not known during some of 1998, expectations about which countries would participate in monetary union were probably driving some of the movements in the pseudo-euro. On balance, given these problems, it would probably be best to ignore the euro futures data and concentrate on the fourteen months of actual euro data available since January 1999.

Third, the focus of this paper is on daily exchange rate movements. While the author does not attempt to specify which economic agents the paper is concerned with, this is an important issue when the periodicity is being considered. Focusing on daily exchange rate movements provides ample observations and may be relevant for financial institutions, but are extreme daily exchange rate movements of 
relevance to companies, who are presumably more interested in exchange rate movements over a longer time period such as weeks or months?

Fourth, an interesting tension between the role of 'noise traders' in providing depth to the market but possibly imposing economic costs of excess volatility to economic agents such as financial institutions or commercial companies is not touched upon.

Professor Brendan Walsh: I would like to join in the expressions of appreciation to John Cotter for his research on the interesting topic of exchange rate volatility. His application of the GARCH model to Irish data breaks new ground. The results in Figures 3, 4, 5 and 6 are useful summaries of the uncertainty in the bilateral euro/Irish pound and sterling/Irish pound exchange rates. The estimates of the conditional variance appear to resemble the unconditional variance fairly closely. But clearly there were periods of turbulence such as the currency crisis of 1992-93 and later in the 1990s when entry into EMU loomed. Rational expectations would imply that people's predictions of volatility would change during these periods. The merit of the paper is that it models how expected volatility changed over time.

While the focus of the paper is on the definition and measurement of the phenomenon, in the third section the author touches on the repercussions of volatility. There is an underlying assumption that volatility is undesirable and costly, and by implication that joining a currency union is beneficial because it eliminates volatility. The author rightly asks whether adopting the euro implies reduced overall volatility for Ireland compared with the alternative of floating. Leaving this issue aside, however, I think we should not too readily accept that volatility is seriously damaging to the economy. The Irish decision to break the link with sterling in 1979, in order to enter a "zone of monetary stability" in Europe, is a fascinating case study. The evidence suggests that the introduction of volatility had remarkable little effect on the real economy. Consider the following:

1. During the period of the sterling link, the relative importance of the UK in Irish trade declined steeply. From roughly 70 percent after the Second World War, the UK's share of our combined imports and exports had fallen to just under 50 percent by 1978 . The currency union did not counter this trend.

2. More importantly, there is no evidence of a structural break in the behaviour of Anglo-Irish trade after the break-up of the currency union. While the UK's share of our trade continued to decline after 1978, it less than 30 percent by the end of the century, the absolute volume of trade continued to grow in line with the growth in the two economies. There was a pause in the early 1980s, but this was due to the severe recession rather than the dissolution of the currency union. By 1998 the volume of Anglo-Irish trade was three times the 1978 level. This is exactly in line with what would have been predicted on the basis of the pre-1979 relationship between trade and the level of output in the two economies. 
It is remarkable that such a dramatic event as the break-up of the currency union, and the introduction of volatility into the IEP/GBP exchange rate, should have had so little effect on the real trading economy. It is important to publicise this finding given the belief that Ireland's change of exchange rate regime had serious adverse effects has been used to buttress the belief that participating in a currency union has a major impact on the pattern of trade. By implication the absence of any adverse repercussions from the break-up of a currency should dampen expectations of major gains as a direct consequence of entering a monetary union like EMU.

Mr. Shane Whelan: Thank you, Dr. Cotter, for presenting an interesting paper. Exchange risk, as you point out, requires two parameters to characterise it properly - some measure of spread (standard deviation, inter-quartile range, etc) and some measure of the thickness of the tails (tail index, mean excess function, etc). One can generally get a good estimate of the spread, as this is where, by construction, the majority of data points lie. However, the thickness of the tails pose a more challenging statistical problem as, by construction, few data point lie in the tails.

You use the Hill estimator to estimate the tail index. This continues to be regarded as the best single estimator for this purpose but with the considerable caveat that it is the best of a bad lot. The Hill estimator to known to be strongly biased in samples of the order studied here, even in the independent and identically distributed case (Pictet et al. (1998)). When the data set exhibits the conditional dependencies evidenced in the data set studied then there is some doubt even about its asymptotic properties (Embrechts et al., 1997). The results you cite therefore can, at best, be regarded as a broad guide.

On the economic side of your analysis, I must confess a difficulty in interpreting your results. It would be better, I think, if the statistical analysis is based on a weighted average of our exchange rate to those of other economies, the weights reflecting the economic importance of the economy concerned to our own. The Central Bank of Ireland has maintained and published such an index, the Trade Weighted Index, for upwards of the last two decades. An analysis of this index, before and after the introduction of the euro, might give a better indication of the overall economic significance of changing volatility and tail index. The problematic small number of data points with the euro exchange rate can be handled, albeit imperfectly. by backdating the euro as both the weights and entry levels of each constituent currency is known.

\section{References}

Pictet, O.V., M. M. Dacorogna and U. A. Müller, 1998. "Hill, Bootstrap and Jacknife Estimators for Heavy Tails", in R.J. Adler, R. E. Feldman, and M. S. Taqqu (eds.), A Practical Guide to Heavy Tails: Statistical Techniques and Application, Birkhäuser.

Embrechts, P., C. Klüppelberg, T. Mikosch, 1997. Modelling Extremal Events. Springer, Berlin. 
Professor Brendan Whelan: I would like to thank the author for a very interesting paper. I have two questions. The first relates to the reliability of the estimates in Table 7. Given the relatively short runs of data, and the fact noted by the author that extreme values tend to be temporally bunched, would the estimates be prone to large sampling errors? Secondly, and this is something on which Jim Power might also like to comment, would the conclusions of the paper be affected by the fact that the exchange rate impacts on a firm not just through its effect on export prices but also through the prices of imported inputs. Thus, for instance, if a firm has sterling sales that were exactly matched by purchases of inputs from the UK, the effect on that firm of sterling fluctuations is entirely eliminated. Do we know enough about the import/export balance at individual firm level to assess this? 
